\title{
Attention to Prescriptive Norms Increases Dictator Game Generosity in Women but not Men: Using the 2D:4D Digit Ratio to Test the Role of Biology
}

\author{
Carlos Maximiliano Senci ${ }^{1}$, Fermín Breccia $^{2}$ and Esteban Freidin ${ }^{1,{ }^{*}}$ \\ ${ }^{1}$ Instituto de Investigaciones Económicasy Sociales del Sur (IIESS), Conicet Bahía Blanca, Bahía Blanca, \\ Argentina \\ ${ }^{2}$ Instituto de Psicología Básica, Aplicaday Tecnología (IPSIBAT), Conicet Mar del Plata, Mar del Plata, \\ Argentina
}

\begin{abstract}
Some authors propose that gender norms pose divergent effects on generosity, usually being women the gender expected to be kinder. Indeed, some economic experiments show women to be more generous than men in the Dictator Game (DG). Despite some claiming these results to be determined by socialization into gender norms, data do not speak against a biological explanation of sex differences. In fact, there is evidence that DG generosity varies with the level of pre-natal exposure to testosterone and estrogens, as indirectly measured using participants' 2D:4D digit ratios. In any case, it is unclear whether DG generosity expresses pure altruism or compliance with social norms. Socialization and biological factors may have diverse effects on these two different motivations. In the present study, we aimed at contributing to this discussion. We randomly assigned participants to two independent conditions. In the prescriptive norm condition, participants were incentivized to accurately estimate others' opinion about the most socially appropriate option in the DG (i.e., the prescriptive norm), and then made their decisions as dictators. Participants in the control conditions made their decisions as dictators without any prior estimation. We found that the normative exercise increased generosity (relative to the control condition) in women but not in men. In a sub-sample, we also measured participants' 2D:4D digit ratios as a proxy of a socialization-free sex-dimorphic hormonal influence on behavior. We found no evidence that the normative effect of the estimation exercise was modulated by participants' digit ratios. In contrast, generosity in the control condition was higher, the more extreme (highest and lowest) the digit ratios were. We conclude in favor of: 1) a socialization-modulated gender effect on responses to prescriptive norms of generosity; and 2) a biological effect of pre-natal hormonal levels on generosity when the norm was not elicited; in this last case, the relationship between pre-natal testosterone and empathic concern might be involved.
\end{abstract}

Keywords: Other-regarding preferences, Altruism, Gender, Digit ratio.

\section{INTRODUCTION}

The socio-psychological literature on social norms makes the distinction between descriptive and prescriptive or injunctive norms [1, 2]. These categories refer to people's expectations about what most people do and what people believe it is the socially appropriate thing to do, respectively [3]. Converging lines of evidence from cultural anthropology [4-6] and sociology [7], through social psychology [8, 9] and behavioral economics [10-12], to neuroscience [13,14] suggest that people follow norms at levels that could not be predicted from selfish instrumental reasons alone. Indeed, social norms have been shown to influence a myriad of behaviors relevant to vital societal issues, such as, voting [15], tax collection [16], bribery [17, 18], littering [19], cheating [20], and stealing [21], among others. Therefore, understanding how and when norms affect behavior could mean a relevant step towards

*Address correspondence to this author at the Instituto de Investigaciones Económicasy Sociales del Sur (IIESS), Conicet Bahía Blanca, Bahía Blanca, Argentina;

E-mail: efreidin@iiess-conicet.gob.ar improving social welfare and adequately orienting policy decisions. We here focused on the effect of prescriptive norms on economic decisions in a nonstrategic context, namely the Dictator Game (DG).

There are different variants of the DG, but at its core lays a unilateral decision with payoff consequences for the decision maker and a passive associated participant. In this context, decisions can be seen as more or less generous depending on the relative payoff each gets. Despite the selfish rational choice involves the dictator keeping the whole pie for herself, modal transfers are typically greater than zero, and many dictators even transfer half the endowment (see [22] for a meta-analysis of DG results). Avoidance of large departures from the norm of fair share is a motivation that may underlie non-selfish decisions in the DG [23, 24]. In line with this, the Morality Salience Hypothesis posits that prosociality in games such as the DG is driven by a generalized morality preference that motivates people to do what they think is morally right [25-27], and recent reports indeed show that making participants think of what they believe is morally best in the game induces greater altruism [28]. 
In addition to egalitarian norms for sharing material resources, differences between women and men, and gender and its associated norms and stereotypes have attracted the attention of researchers as possible proximate factors moderating generosity and altruism in economic games [29-32]. Willer, Wimer, Lindsay, and Owens [33] mention that gender is among the most consistent demographic predictors of charitable giving, being women typically more generous than men. Earlier meta-analyses in the social psychological literature on pro-social behaviors suggest, in contrast, that men help more than women in the context of shortterm encounters with strangers [34], that is, a situation similar to a DG. In turn, there is no consensus regarding who is the more generous gender in the experimental economics literature. Engel's [22] metaanalysis of DG decisions showed women to be more generous than men, though Niederle [31] cautioned about that result because the vast majority of studies reviewed by Engel did not report participants' gender, which could hide a publication bias. In sum, some economic experiments report women's DG giving to be greater than that of men (e.g., [32, 35-38]); but, this pattern is not always found (e.g., [39-42]) and can even reverse $[41,43]$.

Eagly [44] and Wood and Eagly [45] propose that gender norms derive from the division of labor between women and men and the subsequent inference that each gender has intrinsic qualities making it especially apt for specific tasks. In industrialized societies, women are typically expected to be more communally oriented and to show caring and unselfish behaviors, whereas men are expected to show instrumental, autonomous, and independent attitudes [46, 47]. In fact, there is evidence from economic experiments showing that women are expected to be more generous than men $[32,48]$. If this represents general social expectations, women and men may usually live under the pressure to conform to such social stereotypes, and may even show such inclinations in laboratory economic games $[49,50]$.

According to the Social Heuristic Hypothesis, participants bring to the laboratory and enact in economic experiments everyday successful strategies [49]. Rand and collaborators [50] claim that participants are even more prone to apply their common heuristics in the lab if they are prompted to act unreflectively (this is so because reflection may inhibit automatic routines [51]). Given gender norms prescribing communal and unselfish behaviors in women [46], Rand, Brescoll, Everett, Capraro, and Barcelo [52] predicted and found that experimental procedures inducing intuitive (in contrast to reflective) responses led women, but not men, towards higher sharing in the DG. Moreover, this effect was moderated by participants' explicit sex role identification, namely the extent to which they identify themselves with their sex-corresponding gender stereotype [52]. From this, the authors concluded in favor of a socialization pathway leading women towards increased generosity. Despite Rand et al.'s [52] findings being consistent with a gender effect on DG, we believe that their data do not exclude biological sexual differences as effective variables. Indeed, sex role identification can correlate with a person's 2D:4D digit ratios [53-55], which is a sex-dimorphic proxy of pre-natal exposure to testosterone and estrogens [56]. Moreover, some authors claim that women show an innate tendency to be more empathic than men (e.g., see [57]), which may underlie gender differences in pro-sociality and altruism.

The goal of the present study was to contribute to the discussion on whether differences in the effect of norms on DG generosity between women and men can be modulated by biological sexual differences. In the heart of Gender Roles Theory, authors recognize that the effects of gender roles on behavior could be modulated by pre- and post-natal hormonal processes $[44,45]$, meaning that, as it has been shown for other social preferences such as cooperation [58], norm compliance may be affected by the interaction of social and biological events. In fact, various studies have found a relationship between people's digit ratios and their generosity in DGs (briefly reviewed in [59] but also see 42,60 ). However, decisions in the DG may not be straightforward to interpret. Despite the simplicity of the game, diverse motivations may underlie DG decisions, which do not unambiguously express a preference for altruism but may also reflect an inclination to comply with salient social norms [61]. The present study contributes to assessing whether participants' digit ratios predict their DG generosity in situations with more or less salient norms.

With this goal in mind, we investigated the extent to which participants' responses to the prescriptive norm in the $D G$ were modulated by their $2 \mathrm{D}: 4 \mathrm{D}$ digit ratios as a socialization-free proxy of sex hormonal influences on behavior, and compared this against a control group which made DG decisions without any prior normative exercise. The 2D:4D digit ratio is the length of the index finger divided by the length of the ring finger of a person's hand. Digit ratios within a given population typically show sexual dimorphism: males usually have 
lower digit ratios than females [56]. This sex difference has been linked to higher pre-natal exposure to testosterone in men than in women, and the reverse for estrogens (see [56]). Also important, it is the fact that pre-natal exposure to these hormones is not systematically linked to their presently circulating levels [62]. Not only that, but digit ratios have been associated with various social behaviors, such as, for example, aggression, competitiveness [56], and, especially relevant for present purposes, DG decisions $[59,63,64]$.

In the present study, we implemented two independent treatments. In the prescriptive norm condition, participants had to guess others' opinion about which was the most socially appropriate option in the DG before making their decisions as dictators. It is common that people perceive a fairness norm -which prescribes a 50-50 sharing rule-as applying to the DG $[23,24]$. The present design allows assessing the extent to which focusing participants' attention on the prescriptive norm affect their DG decision, and, to our knowledge, is the first study to evaluate whether such normative effect depends on gender and can be modulated by different levels of pre-natal exposure to sexual hormones.

According to Norm Focus Theory, the cognitive accessibility of normative information is a crucial factor determining its efficacy on behavior [19]. Therefore, we expected participants in the prescriptive norm condition to be more generous than those in the control condition (see [65]). In addition, under the assumption of the Social Heuristic Hypothesis [50] that participants enact everyday successful strategies in the lab, we expected the activation of the prescriptive (fair-share) norm to have a more pronounced effect in women than in men, given presumed divergent gender norms in society [46, 52]. If the effect of the prescriptive norm on DG decisions is modulated by participants' digit ratios, it would be evidence in favor of a socialization-free effect of pre-natal hormones on norm compliance. Otherwise, we would feel inclined to attribute a difference in the prescriptive effect on generosity between women and men to socialization into gender roles.

\section{METHODS}

\section{Participants and Task}

Present protocols were reviewed and approved by the Bioethical Committee of the Hospital Municipal "Dr. Leónidas Lucero", Bahía Blanca, Argentina. 178 undergraduates participated in this experiment (mean age $\pm 1 \mathrm{SD}=23 \pm 4$ years old; $55 \%$ women) at the Universidad Nacional del Sur, Bahía Blanca, Argentina, in the second semester of 2015, the first semester of 2016, and the second semester of 2017. Participants were recruited via e-mail invitations from a preregistered subject pool consisting of undergraduate and graduate students from different educational institutions in Bahía Blanca.

We ran eight sessions, and each participant took part just once. Experimental sessions were always run on either Tuesdays, Wednesdays, or Thursdays at the same time of the day (12:30) and place (Universidad Nacional del Sur), using paper and pencil, and lasted for approximately $45 \mathrm{~min}$. Participants received $\$ 25$ (approx. u\$s 2.5 at the time of the study) as show-up fee.

Upon arrival, participants seated in individual chairs, and the session began with a brief oral presentation, including basic details about the DG and how roles were assigned. Participants were told that they would play with another participant present in the room, but that they would not be able to identify each other during or after the session. Following the procedure used by Krupka and Weber [65], in all conditions, participants were informed that they would make their DG decisions as proposers without knowing their actual role. Participants were informed that they would know the role randomly assigned to them at the end of the session, at the moment of receiving their payment. Throughout the session, however, we emphasized that participants' decisions would only affect payoffs if they were later assigned the role A (proposer); on the contrary, if they were later assigned the role $B$ (receiver), decisions made in role $A$ would be inconsequential.

After that, participants received the written instructions which included every detail participants needed to know about the game (decision options, payoffs, the consequences of role assignment, etc) and how the session would unfold. To ensure understanding of the instructions, we asked participants to answer a series of control questions which were individually checked before participants could proceed to make their decisions (see an English translation of the written instruction on request).

The procedure used here was based on the prescriptive focus condition done by Krupka and Weber [65]. They used a two-options DG in which US university students could choose an equitable share ( $\$ 5$ to the proposer and $\$ 5$ to the receiver) or a selfish socially inefficient option ( $\$ 7$ for the proposer and $\$ 1$ 
for the receiver). In the present procedure, instead of Krupka and Weber's dichotomous DG, we used a continuous DG in which each participant had to divide $\$ 50^{1}$ between her/himself and her/his associated participant. To make the decision, a participant had to write two numbers to fill the following sentence: "I choose to keep $\$$ _ and that B keeps $\$$ _."

We ran two independent conditions: the Control condition $(n=66)$, and the Prescriptive Norm condition $(\mathrm{PN} ; \mathrm{n}=112){ }^{2}$ In the Control condition, participants, first, decided as proposers in a $\$ 50$-pie DG, and, second, responded a post-decision questionnaire. In condition PN, participants were first asked to accurately estimate others' modal opinion about which was the most socially appropriate decision in the DG; second, they made their decisions as proposers in the \$50-pie DG; and last, they responded the post-decision questionnaire.

The initial estimation exercise in condition PN involved guessing, for each of ten ranges of distributions (money the dictator could keep for her/himself in increments of 5 : $\$ 0-5, \$ 6-10, \ldots, \$ 46-50$ ), the percentage of previous participants who had chosen it as the most socially appropriate decision range. In condition PN, some participants $(n=76)$ could win a bonus payment of $\$ 25$, if, first, chose the proper range as the most chosen, and, second, their estimation did not differ by more than three percentage points from the percentage of control participants that had chosen that range. For other participants in

\footnotetext{
'The sign "\$" always refers to Argentine pesos in this article.

2 Krupka and Weber [65] incentivized the accurate estimation of the prescriptive norm, thus implying that two aspects of their protocol differed between the normative condition and the control condition: 1) the estimation of the prescriptive norm; and 2) the possibility of obtaining an extra monetary earning before making the DG decision. This feature of their protocol is methodologically problematic to securely infer a normative effect, because the non-normative factor could have been effective. To control for this, in the first five sessions of this experiment, we had three independent conditions that differed in the event prior to the DG decision: 1) in condition PN (for Prescriptive Norm), participants were incentivized to accurately estimate the prescriptive norm $(n=36) ; 2)$ in condition PN_WO, participants had to estimate the prescriptive norm but were not incentivized to do it accurately (WO for WithOut incentive; $n=36$ ); and 3 ) in the control condition, there was no prior event $(n=24)$. A Kruskal Wallis ANOVA by Ranks comparing the decisions among the three conditions (PN, PN WO, and control) showed significant differences $\left(X^{2}=7.91, \mathrm{df}=2, \mathrm{P}<0.05\right)$. After the normative estimation, participants in condition PN decided to keep a smaller amount of money than participants in the control condition (Mann-Whitney $U$ test, $U=235, Z=2.79, P<0.01$ ). DG decisions in condition PN WO were more generous than in the control as well (Mann-Whitney $U$ test, $U=286.5, Z=2.228, P=0.02$ ), and the comparison of the amount of money kept between conditions PN_WO and PN showed no significant differences (Mann-Whitney $U$ test, $U=594.5, Z=-0.90, P=0.36$ ). This pattern of results thus suggests that the estimation exercise had a normative effect on generosity irrespective of whether it was monetarily incentivized or not. Given the lack of significant difference between conditions PN and PN_WO, for the remaining analyses in this paper we pulled together the data from these two conditions, thus having $n_{P N}=112$.
}

condition PN $(n=36)$, the normative estimation was not incentivized. Because we found no differences between the effect of incentivized and non-incentivized estimations on decisions, we pooled these participants together as explained in footnote \#2. All participants in condition PN were told that the right answer for the estimation exercise was written in a sheet which was inside an envelope that was placed on a desk in the front, and that it was going to be opened and showed to them at the end of the session.

Post-decision questionnaires asked for the (nonincentivized) estimation of the DG descriptive norm in the session (estimation of the modal decision in the DG), each participant's personal norm (their opinion about what was the most socially appropriate decision in the DG), and socio-demographic information (gender, age, number of known participants in the session, number of previous participations in economic experiments, among others).

Finally, we were interested in measuring participants' 2D:4D digit ratios. With this goal in mind, participants from the last three sessions had their two hands scanned just before payment (Control condition, $n=42$; $P N$ condition, $n=42$ ). Before we began scanning hands, we again explained participants that their participation was voluntary, and that we needed to scan their hands to obtain their digit ratios, which was a measure that had been correlated with some behaviors. We reassured again the anonymity of the stored data and confidentiality in their use. No participant refused to have her/his hands scanned.

We followed Neyse and Brañas-Garza's [66] guide for obtaining and measuring digit ratios. The scanner used was an Epson Perfection v350, all scans were made in color and in a $300 \mathrm{dpi}$ resolution. As participants finished filling out the post-decision questionnaire, they were asked to form a line in front of the scanner where they were met by two of the experimenters. One of the experimenters operated the computer (which had a screen that was out of the participant's sight) while the other received the sociodemographic form, wrote the participant's code in a piece of paper, and instructed the participant to place both hands flat in the scanner over the code paper (which was placed in a bottom corner of the scanner). We ran a "preview" of the scanned hands to make sure they were placed properly, and aided the participant to re-frame them if they were not. We repeated this procedure until we obtained a clear and full image of the participant's hands. After making sure the hands were framed properly, we proceeded to scan the hands 
in a 300 dpi resolution and checked the scanned image before instructing the participant to return to her/his seat. Subjects were also asked to remove any rings from their hands before the scan, and if a ring mark was noticed in the scan or in their hands, they were asked to return to their seats and rub their hands for a bit before returning to the line.

We discarded a male participant from the control condition who reported having had a broken relevant finger. The week after the session, we measured the digit ratio for each hand using the ruler tool of a general purpose photo editing software, and then measured again ten days after that. We obtained correlations of 0.971 and 0.956 for the right and left hands, respectively. These results indicated robust measurement [66]. The digit ratio measure used in the following analyses was the average of first and second measurements. The data that support the findings reported in this study are openly available in Open Science Framework at https://osf.io/jkqm9/?view_only=69b7b012401c496598 $351 \mathrm{~b} 45 \mathrm{f} 7336 \mathrm{f} 35$.

\section{RESULTS}

As expected, participants in condition PN estimated (mean \pm 1 sem) that previous participants' opinion about the most socially appropriate option to divide the $\$ 50$ in the DG would be close to the $\$ 25-\$ 25$ fair share (to keep $\$ 26.38 \pm 0.84$ ), which, in fact, was not significantly different from control participants' reported personal norm (to keep $\$ 25.29 \pm 0.5$; Mann-Whitney $U$ test, $U=378, Z=0.47 ; p=0.64$ ).

To analyze DG decisions, we report a Tobit regression (lower limit: 0; upper limit: 50) with condition, the interaction of Condition $x$ Gender, and several controls as predictors (see Figure 1). The Condition $x$ Gender interaction turned out to be significant at the $10 \%$ level. Figure 2 and nonparametric tests allowed us to further explore the meaning of that result. Women's DG decisions showed significantly higher generosity after the normative estimation exercise than in the Control condition (Mann-Whitney $U$ test, $U=433, Z=2.68, p<0.007$ ). In contrast, the difference in men's DG decisions between $P N$ and Control was not significant $(U=523, Z=-0.46$, $p=0.64)$. Therefore, we found a gender difference in the effect of the normative estimation exercise on DG decisions. Whereas women showed higher generosity after thinking of the prescriptive norm (relative to women in the control condition), men did not.

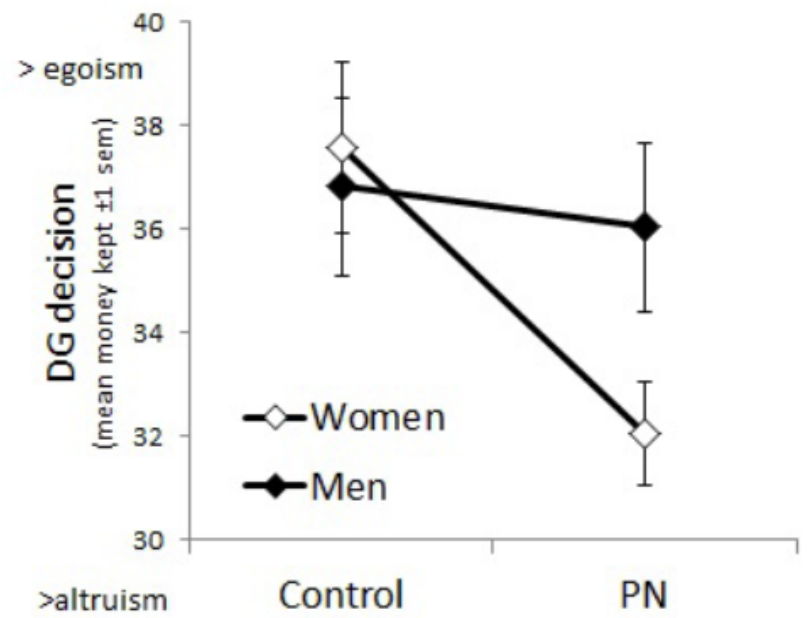

Figure 2: Amount of money (mean \pm 1 sem) kept by dictators (from a total of $\$ 50$ ) as a function of gender and condition. Control: participants who had no estimation exercise prior to the DG decision; PN: participants who estimated the Prescriptive Norm before making the DG decision.

Figure 3 shows the descriptive statistics for rightand left-hand digit ratios of women and men from the

\begin{tabular}{|ccc|}
\hline DG Decision (egoism) & $\mathbf{( 1 )}$ & (2) \\
\hline Condition & $-0.32(2.63)$ & $45.30(66.17)$ \\
Gender & $0.77(2.87)$ & $0.90(2.88)$ \\
Condition ${ }^{*}$ Gender & $-6.13(3.65)^{\star}$ & $-6.76(3.68)^{\star}$ \\
Age & & $-0.23(0.24)$ \\
Known participants & & $-0.42(0.88)$ \\
Number of previous part & & $-0.13(0.52)$ \\
Intercept & $38.18(1.97)^{\star \star \star \star}$ & $43.84(5.72)^{\star \star \star \star}$ \\
\hline $\mathbf{N}$ & $\mathbf{1 7 8}$ & $\mathbf{1 7 8}$ \\
\hline
\end{tabular}

${ }^{*} \mathrm{P}<0.10 ;{ }^{* *} \mathrm{P}<0.05 ;{ }^{* * *} \mathrm{P}<0.01 ;{ }^{* * *} \mathrm{P}<0.001$.

Figure 1: Coefficients (standard errors) from Tobit regression models. Condition: $P N=1$, Control=0; Gender: Women=1, Men=0; Studies: Economics, Business and Administration=1, Others $=0$. 


\begin{tabular}{|c|c|c|c|c|c|c|}
\hline & $\mathbf{N}$ & Mean & Median & SD & Min & $\operatorname{Max}$ \\
\hline \multicolumn{7}{|l|}{ Right hand } \\
\hline Women & 37 & 0.9548 & 0.9533 & 0.0284 & 0.8921 & 1.0101 \\
\hline Men & 46 & 0.9467 & 0.9450 & 0.0301 & 0.8796 & 1.0265 \\
\hline \multicolumn{7}{|l|}{ Left hand } \\
\hline Women & 37 & 0.9652 & 0.9599 & 0.0333 & 0.9066 & 1.0262 \\
\hline Men & 46 & 0.9477 & 0.9445 & 0.0305 & 0.8961 & 1.0087 \\
\hline
\end{tabular}

Figure 3: Descriptive statistics of digit ratios as a function of hand (right and left) and gender (women and men).

present Argentine sample. The four sub-samples (gender $x$ hand) were all normally distributed (women's right-hand digit ratio: Lilliefors, $P>0.20$; Shapiro-Wilk $\mathrm{W}=0.99, \quad \mathrm{P}>0.87$; women's left-hand digit ratio: Lilliefors, $P>0.20$; Shapiro-Wilk $W=0.97, P>0.28$; men's right-hand digit ratio: Lilliefors, $P>0.20$; Shapiro-Wilk $\mathrm{W}=0.98, \mathrm{P}>0.75$; men's left-hand digit ratio: Lilliefors, $P>0.20$; Shapiro-Wilk $W=0.96, P>0.17$ ). An ANOVA with sex as between-subject factor and right/left digit ratios as within-subject factors showed a significant main effect of sex, $F(1,81)=4.10, p=0.046$ (lower mean digit ratios for men than women) and of hand, $F(1$, 81 ) $=5.38, p=0.023$ (lower mean right-hand than lefthand digit ratios), and an almost significant sex-hand interaction, $F(1,81)=3.68, p=0.059$.

We were particularly interested in testing whether digit ratios had a modulatory effect on DG decisions as a function of condition and gender. With this goal in mind, we ran several models of Tobit regressions (lower limit: 0; upper limit: 50). Some authors found non-linear effects of digit ratios on DG decisions (see [63]). Following them, we constructed a variable named Quadratic Difference Digit Ratio (QD-DR) which involved the second power of a participant's digit ratio minus the mean digit ratio of her/his gender.

In Figures $\mathbf{4}$ and 5, we present the results from Tobit regression models for women and men done separately. The dependent variable was always the amount of money kept by the dictator (we also ran the regressions with the natural logarithm and $\log 10$ of DG decisions, but we did not report these results because they were qualitatively very similar to the ones presented here). Both tables contain 3 models: (1) condition ( $P N=1$; Control=0), and left and right digit ratios as predictors (we also ran regressions with a gender-free measure of digit ratios -by subtracting women or men's average digit ratio to each participant's digit ratio, but we do not report these results because they did not qualitatively differ from the ones reported); (2) condition, left and right digit ratios,

\begin{tabular}{|c|c|c|c|c|}
\hline DG Decision & (1) & (2) & (3) & Control (only) \\
\hline Condition & $-7.89(3.27)^{\star \star}$ & $-8.26(3.28)^{\star *}$ & $-7.64(3.47)^{\star *}$ & \\
\hline Right DR & $30.91(81.39)$ & 19.02(80.92) & $23.40(87.19)$ & 74.91(134.97) \\
\hline Left DR & $-70.36(67.39)$ & $-69.83(68.77)$ & $-71.44(73.11)$ & $-139.88(113.42)$ \\
\hline Right Quad Diff DR & & $-2263(1752)$ & $-2315.24(1799.3)$ & $-5671(2486)^{\star *}$ \\
\hline Left Quad Diff DR & & $661.43(1251.27)$ & $647.41(1248.70)$ & $2000(2306)$ \\
\hline Age & & & $-0.07(0.43)$ & $0.43(0.79)$ \\
\hline Known part & & & $0.09(1.42)$ & $-0.74(2.29)$ \\
\hline Number of prev & & & $-0.03(0.73)$ & $1.62(1.24)$ \\
\hline Politics (left-right) & & & $1.01(1.51)$ & $3.26(3.48)$ \\
\hline Intercept & $75.81(52.37)$ & $78.72(53.34)$ & $82.80(54.97)$ & $78.02(98.41)$ \\
\hline $\mathbf{N}$ & 37 & 37 & 37 & 18 \\
\hline
\end{tabular}

${ }^{*} \mathrm{P}<0.10 ;{ }^{* *} \mathrm{P}<0.05 ;{ }^{* * *} \mathrm{P}<0.01 ;{ }^{* * * *} \mathrm{P}<0.001$.

Figure 4: Women only: Tobit regression coefficients (standard errors) for the amount of money kept by the dictator (last column includes women only in the control condition). 


\begin{tabular}{|c|c|c|c|c|}
\hline DG Decision & (1) & (2) & (3) & Control (only) \\
\hline Condition & $-2.06(2.67)$ & $-1.78(2.71)$ & $-0.36(2.91)$ & \\
\hline Right DR & $-2.86(65.78)$ & $-7.15(66.11)$ & $-42.37(69.31)$ & $-64.84(92.25)$ \\
\hline Left DR & $-29.25(58.87)$ & $-31.40(59.37)$ & $10.92(64.69)$ & $-21.19(79.92)$ \\
\hline Right Quad Diff DR & & $-1142(1337)$ & $-1246(1347)$ & $-4396(2163)^{\star *}$ \\
\hline Left Quad Diff DR & & $569(1301)$ & $824(1295)$ & $2801(1812)$ \\
\hline Gender (woman=1) & & & $-3.17(2.73)$ & $2.05(3.59)$ \\
\hline Age & & & $-0.28(0.35)$ & $-0.68(0.49)$ \\
\hline Known part & & & $0.23(1.22)$ & $-0.74(2.29)$ \\
\hline Number of prev & & & $0.25(0.69)$ & $2.28(0.85)^{\star *}$ \\
\hline Politics (left-right) & & & $1.72(1.33)$ & $1.59(1.88)$ \\
\hline Intercept & $67.77(44.65)$ & $73.78(44.79)^{*}$ & $66.66(45.73)$ & $89.10(74.29)$ \\
\hline $\mathbf{N}$ & 37 & 37 & 37 & 18 \\
\hline
\end{tabular}

${ }^{*} \mathrm{P}<0.10 ;{ }^{* *} \mathrm{P}<0.05 ;{ }^{* * *} \mathrm{P}<0.01 ;{ }^{* * * *} \mathrm{P}<0.001$

Figure 5: Men only: Tobit regression coefficients (standard errors) for the amount of money kept by the dictator (last column includes men only in the control condition).

and left and right QD-DR as predictors; and (3) condition, left and right digit ratios, left and right QD-DR as predictors, and some socio-demographic and control variables (i.e., age, left-right politics, known participants in the session, and number of previous participations in economic experiments).

As can be seen in Figures $\mathbf{4}$ and $\mathbf{5}$, the condition effect was only significant for women, it was not modulated by any measure related to digit ratios, and it was robust to the inclusion of socio-demographic and other controls. Digit ratios did not modulate the effect of condition on decisions for women and men taken together either (we did not present these results for brevity). Overall, digit ratios or related measures never had any significant effect on DG decisions or modulated the effect of condition on DG decisions.

Finally, results from previous research suggest that the enactment of gender roles in DG decisions could be modulated by whether sessions were run with mixed sexes or not [36, 40, 41]. Present sessions all included both sexes. Nonetheless, the sex ratio varied across sessions (five sessions had a majority of women $-63 \%$, $84 \%, 64 \%$, 66\% and $56 \%$-, one session had $50 \%$ women; and two sessions had a majority of men $-41 \%$ and $36 \%$ women). We ran Tobit regressions (lower limit: 0; upper limit=50) with DG decision as dependent variable and sex proportion in a session (number of women/total), number of women in a session, and number of men in a session as predictors. None of these predictors resulted significant (all $p$-values $>0.20$ ) in the whole sample, the control condition alone, the $\mathrm{PN}$ condition alone, women alone, or men alone.

\section{DISCUSSION}

In the present study, we found that thinking about the prescriptive norm (what others approve) led women, but not men, to greater generosity in the Dictator Game (DG) relative to control participants who made their DG decision without any prior normative estimation. This gender effect is consistent with Croson and Gneezy's [29] conclusion that women's decisions in the DG (and their other-regarding preferences more generally) are more responsive to social cues than those of men (see also [67]).

The present finding also parallels that of Rand et al. [52] who showed that prompting intuition (automatic behavior) led women, but not men, towards higher altruism in the DG. These authors interpreted their results in terms of a gender role effect, namely the consequence of socially constructed expectations on behavior. According to this view, in many Western societies, women are usually expected to be more kind, caring, and generous than men [44], and such social prescriptions may condition their choices and actions [51]. Gong et al. [41] provided converging evidence on the presumed effect of social expectations on generosity. They did a DG in matrilineal Mosuo, where women commonly have a dominant role in household economic decisions. These authors found that, in contrast to a common pattern found in Western societies [30], Mosuan men's DG offers were much higher than those of Mosuan women [41]. 
Gender Roles Theory also conceives that gender effects can be modulated by pre- and post-natal hormonal influences [45]. For instance, pre-natal exposure to testosterone and estrogens, as indirectly measured through 2D:4D digit ratios, could modulate a person's gender role identification [53-55]. Moreover, different authors have reported a relationship between digit ratios and DG altruism (see [59] for a brief overview). Based on these premises, we also measured participants' digit ratios in the present study. We focused on this variable as a biological measure that could reveal a modulatory effect of pre-natal hormonal levels on the interaction between social norms and generosity. As expected [56, 63], digit ratios showed sexual dimorphism, having women higher digit ratios than men in the present sample. Nonetheless, we could not find evidence that digit ratios modulated the effect of prescriptive norms on DG decisions. This result inclines us to conclude in a similar vein than Rand et al. [52] and Gong et al. [41], namely that the gender difference found is likely due to divergent social pressures towards women and men. (Of course, there may be other biological sexual differences not measured here that may explain present findings). A limitation of the present study is that we did not ask participants to report their explicit sex role identification [68], which could have provided convergent evidence on the role of socialization into gender roles and stereotypes. Interestingly, women did not show higher generosity than men in the control condition, thus suggesting that focusing participants' attention towards the prescriptive norm, as posed in the Norm Focus Theory [19], was the crucial element allowing the gender difference in altruism to appear. This result of a gendered effect of prescriptive norms on generosity contrasts with that of Croson, Handy, and Shang [69] who found that men's intended donations to a hypothetical public radio station were more sensitive than women's to information of the descriptive social norm (others' donations). There are countless differences between Croson et al.'s and the present study, but among the main distinctions is the fact that decisions in their study were hypothetical, implying that their male participants could be inexpensively selfpromoting themselves by conforming to the descriptive norm.

Beyond the effect of norms on generosity, results from the present control condition contribute to discussions in two other fronts.
First, as others before [59], we found a relationship between digit ratios and plain DG altruism (i.e., in the control condition). Brañas-Garza and collaborators [63] interpreted such relationship as indicating that "biological and genetic factors play an important role in social norm transmission" (p. 8). The present significant correlation of digit ratios with decisions from the control condition but not with decisions from the normative condition could be interpreted to suggest otherwise. For instance, pre-natal hormonal effects on generosity could be mediated by differences in other-regarding preferences, such as, empathic concern, more than by variation in mechanisms of norm compliance. Indeed, previous findings negatively link pre-natal testosterone levels with empathic abilities [70], and positively link empathy with altruism $[33,71]$.

In more detail, we found that control participants with more extreme right-hand digit ratio showed higher generosity. This contrasts with results from BrañasGarza et al. [63] and Galizzi and Nieboer [59] who found that Caucasian participants with more extreme digit ratios were more selfish in the DG. Nonetheless, Galizzi and Nieboer [59] did not find any relationship between digit ratios and DG altruism with nonCaucasian participants (Chinese, South Asian, Black, and others). Indeed, digit ratios present strong ethnic variability [56]. A limitation of the present study is that we did not ask participants about their ethnic origin. We believe that asking about ethnicity would be an unusual request in Argentina; for instance, it would have made no sense for participants to identify themselves as Caucasian or not because this is not a category that it is heard of in this country. In any case, genetic studies confirm that the population of Argentina is the result of the intermixing between several groups, including Indigenous American, European, and African populations. The average ancestry for the Argentine sample is approximately $65 \%$ European $(95 \% \mathrm{Cl}$ : $63-$ $68 \%), 31 \%$ Indigenous American (28-33\%) and 4\% African (3-4\%) [72, 73]. More specifically, people from the Province of Buenos Aires (where the present study was run) show $76 \%$ (95\% Cl: $73-79 \%)$ of European ancestry [72]; though such European ancestry is far from homogenous, having dominant groups with ancestry from the Iberian Peninsula and Italy [73]. Therefore, it is possible that the reported difference in the association of right-hand quadratic digit ratio with DG decisions between the present study and those of Brañas-Garza et al. [63] and Galizzi and Nieboer [59] is linked to ethnic differences between the present 
sample and theirs. In any case, it is important to note, however, that the descriptive statistics of digit ratios of different populations of Caucasian participants [59, 63], and even different samples of the same population (university students from the University of Granada [63, 74]) may differ significantly. We do not know at the present the origin and implications of such variability. In addition, another limitation of the present study is the small sample size used compared to that used in the studies by Brañas-Garza et al. [63] and Galizzi and Nieboer [59]. This makes present results relatively less reliable. Last, to have in mind, other reports found no significant association between variation in digit ratios and variations in altruism $[42,60]$, which suggests that that relationship seems rather unreliable.

Second, present results from the control condition also contribute to the ongoing debate on gender and altruism [29-32]. Whereas some studies report women being more generous than men, this pattern is not always found (see the introduction for references). Indeed, control participants' decisions in the present protocol (a plain DG) did not show evidence of a gender effect at all. Boschini et al. [40] showed that a gender effect on altruism could be made appear/disappear as a function of whether sessions were run with mixed genders or not. In fact, a gender effect on generosity was only evident when gender was primed (participants were asked to report it in the beginning) in mixed-gender sessions [40]. In the present protocol, we ran sessions with differing proportions of women and men which allowed us to incorporate information about the gender composition of each session as a predictor in regression analyses. Nevertheless, we could not find any significant effect of this factor on women's or men's generosity. To have in mind, Boschini et al. [40] found a gender effect on generosity only when participants stated their gender before making their DG decision in mixed-gender sessions, whereas, in the present protocol, participants stated their gender in the post-decision questionnaire. This difference could suggest that the gender norm needs to be psychologically active to interact with the gender composition of the session. Nonetheless, the gender differential effect of prescriptive norms on generosity in the present study suggests that gender norms may have been activated in the normative condition. In any case, gender proportions across sessions did not modulate the present normative effect either. This could be simply due to lack of sufficient variation in gender proportions across sessions. We need further research to explore this possibility in more depth.

In brief, we found that women, but not men, were led to higher generosity when they thought of the socially appropriate behavior in a DG before deciding how to share a monetary pie (relative to a control condition without any normative focus before the decision). This gender effect was not modulated by a sex-dimorphic variable such as participants' 2D:4D digit ratios, which was included as a proxy of pre-natal exposure to testosterone and estrogens. In conclusion, present results are consistent with the idea that social norms may affect generosity through socialization into gender roles. Finally, the fact that digit ratios correlated with decisions in the control condition but not in the normative condition suggests that the presumed effect of pre-natal testosterone on generosity could be mediated by variations in empathic concern more than by differences in psychological mechanisms of norm compliance.

\section{ACKNOWLEDGMENTS}

Funding for the present study was provided by CONICET (grant PIP 2014-2016 N N 112-20130100600-CO) and FONCyT (grant PICT 2013-1582) to EF.

\section{AUTHOR CONTRIBUTIONS STATEMENT}

All authors contributed equally to the design and implementation of the reported study (including data collection), and to the writing of this article.

\section{CONFLICT OF INTEREST STATEMENT}

Authors declare no conflict of interest associated with the present study and report.

\section{REFERENCES}

[1] Aronson E, Wilson TD, Akert RM. Social psychology. Upper Saddle River, NJ: Prentice Hall 2010.

[2] Cialdini RB, Goldstein NJ. Social influence: Compliance and conformity. Annual Review of Psychology 2004; 55: 591-621. https://doi.org/10.1146/annurev.psych.55.090902.142015

[3] Bicchieri C. The Grammar of Society. Cambridge: Cambridge University Press 2006.

[4] Richerson PJ, Boyd R. Not by genes alone: How culture transformed human evolution. Chicago: University of Chicago Press 2005. https://doi.org/10.7208/chicago/9780226712130.001.0001

[5] Sober E, Wilson DS. Unto others: The evolution and psychology of unselfish behavior. Cambridge: Harvard University Press 1998.

[6] Chudek M, Henrich J. Culture-gene coevolution, normpsychology and the emergence of human prosociality. Trends 
in Cognitive Science 2011; 15(5): 218-226.

https://doi.org/10.1016/j.tics.2011.03.003

[7] Coleman JS. Foundations of Social Theory. Cambridge: Harvard University Press 1990.

[8] Cialdini RB, Trost MR. Social influence: Social norms, conformity and compliance. In DT Gilbert, ST Fiske, G Lindzey Eds., The handbook of social psychology. McGrawHill 1998; pp. 151-192.

[9] Sripada C, Stich S. A Framework for the Psychology of Norms. In P Carruthers, S Laurence, S Stich Eds. The Innate Mind: Volume 2: Culture and Cognition, 1st ed. Oxford: Oxford University Press 2007; pp. 281-301.

https://doi.org/10.1093/acprof:oso/9780195310139.003.0017

[10] Bowles S, Gintis H. A cooperative species: Human reciprocity and its evolution. Princeton and Oxford: Princeton University Press 2011. https://doi.org/10.23943/princeton/9780691151250.001.0001

[11] Fehr E, Fischbacher U. Social norms and human cooperation. Trends in Cognitive Sciences 2004; 8(4): 185190.

https://doi.org/10.1016/j.tics.2004.02.007

[12] Fehr E, Fischbacher U, Gächter S. Strong reciprocity, human cooperation, and the enforcement ofsocial norms.Human Nature 2002; 13(1): 1-25.

https://doi.org/10.1007/s12110-002-1012-7

[13] De Quervain DJF, Fischbacher U, Treyer V, Schelthammer M, Schnyder U, Buck A, Fehr E. The neural basis of altruistic punishment. Science 2004; 305: 1254-1258.

https://doi.org/10.1126/science.1100735

[14] Ruff CC, Ugazio G, Fehr E. Changing social norm compliance with noninvasive brain stimulation. Science 2013; 342(6157): 482-484 https://doi.org/10.1126/science.1241399

[15] Gerber AS, Rogers T. Descriptive social norms and motivation to vote: Everybody's voting and so should you. The Journal of Politics 2009; 71(1): 178-191. https://doi.org/10.1017/S0022381608090117

[16] Alm J, Bloomquist KM, McKee M. When You Know Your Neighbour Pays Taxes: Information, Peer Effects and Tax Compliance. Fiscal Studies 2017; 38(4): 587-613. https://doi.org/10.1111/1475-5890.12111

[17] Kobis NC, van Prooijen JW, Righetti F, Van Lange PAM. "Who doesn't?" The impact of descriptive norms on corruption. PLoS ONE 2015; 10(6): e0131830. https://doi.org/10.1371/journal.pone.0131830

[18] Abbink K, Freidin E, Gangadharan L, Moro R. The effect of social norms on bribe offers. The Journal of Law, Economics, and Organization 2018; 34(3): 457-474

https://doi.org/10.1093/ileo/ewy015

[19] Cialdini RB, Reno RR, Kallgren CA. A focus theory of normative conduct: Recycling the concept of norms to reduce littering in public places. Journal of Personality and Social Psychology 1990; 58: 1015-1026.

https://doi.org/10.1037/0022-3514.58.6.1015

[20] Gino F, Ayal S, Ariely D. Contagion and Differentiation in Unethical Behavior: The Effect of One Bad Apple on the Barrel. Psychological Science 2009; 20(3): 393-398. https://doi.org/10.1111/j.1467-9280.2009.02306.x

[21] Cialdini RB, Demaine LJ, Sagarin BJ, Barrett DW, Rhoads K, Winter PL. Managing social norms for persuasive impact. Social Influence 2006; 1(1): 3-15. https://doi.org/10.1080/15534510500181459

[22] Engel C. Dictator games: a meta-study. Experimental Economics 2011; 14: 583-610. https://doi.org/10.1007/s10683-011-9283-7

[23] Andreoni J, Bernheim D. Social Image and the 50-50 norm: a theoretical and experimental analysis of audience effects. Econometrica 2009; 77(5): 1607-1636.

https://doi.org/10.3982/ECTA7384
[24] Brañas-Garza P, Rodriguez-Lara I, Sanchez A. Humans expect generosity. Nature Scientific Reports 2017; 7: 42446. https://doi.org/10.1038/srep42446

[25] Capraro V, http://journal.sjdm.org/17/171107/jdm171107.html - note1 Rand DG. Do the Right Thing: Experimental evidence that preferences for moral behavior, rather than equity or efficiency per se, drive human prosociality. Judgment and Decision Making 2018; 13(1): 99-111.

[26] Capraro V, Vanzo A. The power of moral words: Loaded language generates framing effects in the extreme dictator game. Judgment and Decision Making 2019; 14(3): 309-317.

[27] Bilancini E, Boncinelli L, Capraro V, Celadin T, Di Paolo R. "Do the right thing" for whom? An experiment on ingroup favouritism, group assorting and moral suasion. Judgment and Decision Making 2020; 15(2): 182-192. https://doi.org/10.2139/ssrn.3486398

[28] Capraro V, Jagfeld G, Klein R, Mul M, van de Pol I. Increasing altruistic and cooperative behaviour with simple moral nudges. Nature Scientific Reports 2019; 9: 11880. https://doi.org/10.1038/s41598-019-48094-4

[29] Croson R, Gneezy U. Gender Differences in Preferences. Journal of Economic Literature 2009; 47(2): 448-474. https://doi.org/10.1257/jel.47.2.448

[30] Eckel C, Grossman PJ. Men, Women, and Risk Aversion: Experimental Evidence. Handbook of Experimental Economic Results 2008; 1: 1061-1073. https://doi.org/10.1016/S1574-0722(07)00113-8

[31] Niederle M. A Gender Agenda: A Progress Report on Competitiveness. American Economic Review 2017; 107(5): 115-119. https://doi.org/10.1257/aer.p20171066

[32] Brañas-Garza P, Capraro V, Rascón-Ramírez E. Gender differences in altruism on Mechanical Turk: Expectations and actual behaviour. Economics Letters 2018; 170: 19-23. https://doi.org/10.1016/j.econlet.2018.05.022

[33] Willer R, Wimer C, Owens LA. What drives the gender gap in charitable giving? Lower empathy leadsmen to give less to poverty relief. Social Science Research 2015; 52: 83-98. https://doi.org/10.1016/j.ssresearch.2014.12.014

[34] Eagly AH, Crowley M. Gender and helping behavior: A metaanalytic review of the social psychological literature. Psychological bulletin 1986; 100(3): 283-308. https://doi.org/10.1037/0033-2909.100.3.283

[35] Chowdhury SM, Jeon JY, Saha B. Gender Differences in the Giving and Taking Variants of the Dictator Game. Southern Economic Journal 2017; 84: 474-483. https://doi.org/10.1002/soej.12223

[36] Eckel C, Grossman PJ. Are Women Less Selfish Than Men? Evidence from Dictator Experiments. Economic Journal 1998; 108(448): 726-735. https://doi.org/10.1111/1468-0297.00311

[37] Sharma S. Gender and distributional preferences: Experimental evidence from India. Journal of Economic Psychology 2015; 50: 113-123.

https://doi.org/10.1016/j.joep.2015.08.004

[38] Khachatryan K, Dreber A,Von Essen E, Ranehill E. Gender and preferences at a young age: Evidence from Armenia. Journal of Economic Behavior \& Organization 2015; 118: 318-332. https://doi.org/10.1016/j.jebo.2015.02.021

[39] Bolton G, Katok E. An experimental test for gender differences in beneficent behavior. Economics Letters 1995; 48(3-4): 287-292.

https://doi.org/10.1016/0165-1765(94)00621-8

[40] Boschini A, Muren A, Persson M. Constructing gender differences in the economics lab. Journal of Economic Behavior \& Organization 2012; 84(3): 741-752. https://doi.org/10.1016/j.jebo.2012.09.024 
[41] Gong B, Yan H, Yang CL. Gender differences in the dictator experiment: evidence from the matrilineal Mosuo and the patriarchal Yi. Experimental Economics 2015; 18: 302-313. https://doi.org/10.1007/s10683-014-9403-2

[42] Brañas-Garza $P$, Espín AM, García-Muñoz $T$, Kovářík J. Digit ratio (2D : 4D) and prosocial behaviour in economic games: no direct correlation with generosity, bargaining or trustrelated behaviours. Biology Letters 2019; 15: 20190185. https://doi.org/10.1098/rsbl.2019.0185

[43] Andreoni J, Vesterlund L. Which Is The Fair Sex? Gender Differences In Altruism. The Quarterly Journal of Economics 2001; 116: 293-312. https://doi.org/10.1162/003355301556419

[44] Eagly AH.The his and hers of prosocial behavior: an examination of the social psychology of gender. American Psychologist 2009; 64(8): 644-658.

https://doi.org/10.1037/0003-066X.64.8.644

[45] Wood W, Eagly AH. Biosocial construction of sex differences and similarities in behavior. In JM Olson, MP Zanna Eds., Advances in Experimental Social Psychology, Volume 46. Burlington: Academic Press 2012; pp. 55-123. https://doi.org/10.1016/B978-0-12-394281-4.00002-7

[46] Eagly $\mathrm{AH}$. Reporting sex differences. American Psychologist 1987; 42(7): 756-757.

https://doi.org/10.1037/0003-066X.42.7.755

[47] Ochiai E, Molony B. Asia's New Mothers. Folkestone: Global Oriental 2008.

https://doi.org/10.1163/ej.9781905246373.i-232

[48] Aguiar F, Brañas-Garza P, Cobo-Reyes R, Jiménez N, Miller L. Are women expected to be more generous? Experimental Economics 2009; 12: 93-98. https://doi.org/10.1007/s10683-008-9199-z

[49] Peysakhovich A, Rand DG. Habits of virtue: Creating norms of cooperation and defection in the laboratory. Management Science 2015; 62(3): 631-647. https://doi.org/10.1287/mnsc.2015.2168

[50] Rand DG, Peysakhovich A, Kraft-Todd GT, Newman GE, Wurzbacher O, Nowak MA, Greene JD. Social heuristics shape intuitive cooperation. Nature Communications 2014; 5 : 3677. https://doi.org/10.1038/ncomms4677

[51] Rand DG. Cooperation, fast and slow: Meta-analytic evidence for a theory of social heuristics and self-interested deliberation. Psychological Science 2016; 27(9): 1192-1206. https://doi.org/10.1177/0956797616654455

[52] Rand DG, Brescoll VL, Everett JA, Capraro V, Barcelo $H$. Social Heuristics and Social Roles: Intuition Favors Altruism for Women but Not for Men. Journal of Experimental Psychology: General 2016; 145(4): 389-396. https://doi.org/10.1037/xge0000154

[53] Beech JR, Mackintosh IC. Do differences in sex hormones affect handwriting style? Evidence from digit ratio and sex role identity as determinants of the sex of handwriting. Personality and Individual Differences 2005; 39: 459-468. https://doi.org/10.1016/j.paid.2005.01.024

[54] Csathó Á, Osváth A, Bicsák É, Karádi K, Manning JT, Kállai $J$. Sex role identity related to the ratio of second to fourth digit length in women. Biological Psychology 2003; 62: 147156. https://doi.org/10.1016/S0301-0511(02)00127-8

[55] Kastlunger B, Dressler SG, Kirchler E, Mittone L, Voracek M. Sex differences in tax compliance: Differentiating between demographic sex, gender-role orientation, and prenatal masculinization (2D:4D). Journal of Economic Psychology 2010; 31: 542-552. https://doi.org/10.1016/j.joep.2010.03.015

[56] Manning JT. Digit ratio: a pointer to fertility, behavior and health. New Jersey: Rutgers University Press 2002.
[57] Baron-Cohen S, Wheelwright S. The Empathy quotient: An investigation of adults with Asperger syndrome or high functioning autism, and normal sex differences. Journal of Autism and Developmental Disorders 2004; 34: 163-175. https://doi.org/10.1023/B:JADD.0000022607.19833.00

[58] Cecchi F, Duchoslav J. The Effect of Prenatal Stress on Cooperation: Evidence from a Public Goods Game in PostConflict Uganda. European Economic Review 2018; 101: 3556.

https://doi.org/10.1016/j.euroecorev.2017.09.015

[59] Galizzi MM, Nieboer J. Digit ratio (2D:4D) and altruism: evidence from a large, multi-ethnic sample. Frontiers in Behavioral Neuroscience 2015; 9: 41. https://doi.org/10.3389/fnbeh.2015.00041

[60] Parslow E, Ranehill E, Zethraeus N, Blomberg L, von Schoultz B, Lindén Hirschberg A, Johannesson M, Dreber A.The digit ratio (2D:4D) and economic preferences: No robust associations in a sample of 330 women. Journal of the Economic Science Association 2019; doi: 10.1007/s40881019-00076-y

https://doi.org/10.1007/s40881-019-00076-y

[61] List J. On the interpretation of giving in Dictator Games. Journal of Political Economy 2007; 115(3): 482-493. https://doi.org/10.1086/519249

[62] Hönekopp J, Bartholdt L, Beier L, Liebert A. Second to Fourth Digit Length Ratio (2D:4D) and Adult Sex Hormone Levels: New Data and a Meta-Analytic Review. Psychoneuroendocrinology 2007; 32: 313-321. https://doi.org/10.1016/j.psyneuen.2007.01.007

[63] Brañas-Garza P, Kovárík J, Neyse L. Second-to fourth digit ratio has a non-monotonic impact on altruism. PloS One 2013; 8(4): 1-10.

https://doi.org/10.1371/journal.pone.0060419

[64] Buser T. Digit ratios, the menstrual cycle and social preferences. Games and Economic Behavior 2012; 76(2): 457-470. https://doi.org/10.1016/j.geb.2012.07.006

[65] Krupka E, Weber RA. The focusing and informational effects of norms on pro-social behavior. Journal of Economic Psychology 2009; 30(3): 307-320.

https://doi.org/10.1016/j.joep.2008.11.005

[66] Neyse L, Brañas-Garza P.Digit Ratio Measurement Guide. MPRA Paper No. 54134 2014. Retrieved from http://mpra.ub.uni-muenchen.de/54134/

[67] Miller L, Ubeda P. Are women more sensitive to the decisionmaking context? Journal of Economic Behavior \& Organization 2012; 83: 98-104. https://doi.org/10.1016/j.jebo.2011.06.014

[68] Bem SL. On the utility of alternative procedures for assessing psychological androgyny.Journal of Consulting and Clinical Psychology 1977; 45:196-205. https://doi.org/10.1037/0022-006X.45.2.196

[69] Croson R, Handy F, Shang J. Keeping up with the Joneses: The relationship of perceived descriptive social norms, social information, and charitable giving. Nonprofit Management and Leadership 2009; 19(4): 467-489.

https://doi.org/10.1002/nml.232

[70] Chapman E, Baron-Cohen S, Auyeung B, Knickmeyer R, Taylor K, Hackett G. Fetal testosterone and empathy: evidence from the empathy quotient (EQ) and the "reading the mind in the eyes" test. Soc Neurosci. 2006; 1(2): 135-48. https://doi.org/10.1080/17470910600992239

[71] Feldman Hall O, Dalgleish T, Evans D, Mobbs D. Empathic concern drives costly altruism. Neurolmage 2015; 105: $347-$ 356. https://doi.org/10.1016/j.neuroimage.2014.10.043

[72] Avena S, Via M, Ziv E, Pérez-Stable EJ, Gignoux CR, et al. Heterogeneity in Genetic Admixture across Different Regions of Argentina. PLoS One 2012; 7(4): e34695.

https://doi.org/10.1371/journal.pone.0034695 
[73] Homburger JR, Moreno-Estrada A, Gignoux CR, Nelson D, Sanchez E, Ortiz-Tello P, et al. Genomic Insights into the Ancestry and Demographic History of South America. PLoS Genet 2015; 11(12): e1005602. https://doi.org/10.1371/journal.pgen.1005602
[74] Bosch-Domènech A, Brañas-Garza $P$, Espín AM. Can exposure to prenatal sex hormones (2D:4D) predict cognitive reflection? Psychoneuroendocrinology 2014; 43: 1-10. https://doi.org/10.1016/j.psyneuen.2014.01.023

DOI: https://doi.org/10.12974/2313-1047.2020.07.2

(C) 2020 Senci et al.; Licensee Savvy Science Publisher.

This is an open access article licensed under the terms of the Creative Commons Attribution Non-Commercial License (http://creativecommons.org/licenses/by-nc/3.0/) which permits unrestricted, non-commercial use, distribution and reproduction in any medium, provided the work is properly cited. 